\title{
A Study on Passive Cooling Methods by Evaporation and Solar Reflection on Rooftops in a Temperate Climate Region
}

\author{
Suk-Jin Jung ${ }^{1}$ and Seong-Hwan Yoon $*^{2}$ \\ ${ }^{1}$ Ph.D. Student, School of Architecture, Pusan National University, Korea \\ ${ }^{2}$ Associate Professor, School of Architecture, Pusan National University, Korea
}

\begin{abstract}
A number of studies have been carried out on the passive cooling of the outer surface of buildings for the purpose of conserving energy without resorting to fossil fuels, while simultaneously improving the indoor thermal comfort. In addition, the heat island phenomenon has been regarded as a problem. Thus, it is necessary to strive to reduce the thermal load of buildings on the urban environment. In this study, an outdoor experiment was conducted using test specimens with a focus on passive cooling on rooftop surfaces in summertime to clarify the cooling effect of various types of passive rooftop cooling. The influence of rooftop cooling on the indoor heat load, and the heat load of the atmospheric side were also clarified. A total of 10 types of data were collected; case 1 is an AR surface, Cases 2 5 are watered AR surfaces, Cases 6 and 7 are ceramic tiles, with and without water coating or white paint respectively, and finally, Cases 8 and 9 are perforated bricks, with and without a coat of white paint respectively. (1) Results of data analysis for Cases $6 \sim 10$ show that because these types can reduce the load on the air during the day, they are effective. For Cases 7 and 9 and during the day, the heat island effect is suppressed. For Cases 6 9, the tropical night phenomenon can be prevented. (2) In order to reduce the cooling load in summer, the roof slab insulation to reduce heat load in the atmosphere is essential in order to employ an effective passive cooling method. (3) For the insulation standards of the next generation of solar radiation and the evaporation coefficients of 0.5 or 2 and more, 0.1 or 2 can be applied.
\end{abstract}

Keywords: reflection; evaporation; thermal environment: heat load; temperature; air temperature; rooftop; field experiment; air-conditioning load

\section{Introduction}

A number of studies have been carried out on the passive cooling of the outer surface of buildings for the purpose of conserving energy without resorting to fossil fuels, while simultaneously improving the indoor thermal comfort. In addition to this, the heat island phenomenon has been regarded as a problem (Ichinose et al., 1999). Thus, it is necessary to strive to reduce the thermal load of buildings on the urban environment. It is particularly important to examine thermal properties of finishing materials on rooftop surfaces, where the incoming direct solar radiation is considerable.

Based on this, Jayasinghe (2003), Ishikawa (2008) etc. have analysed the indoor energy load or the thermal environment changes that are focused on

*Contact Author: Seong-Hwan Yoon, Associate Professor,

School of Architecture, Pusan National University, Jangjeondong, Busan 609-735, Korea

Tel: +82-51-510-1479 Fax: +82-51-514-2230

E-mail: yoon@pusan.ac.kr

(Received April 8, 2010 ; accepted November 9, 2010) cool rooftops where paints or aluminum foils of high reflection rates have been applied. Takahashi (2003), Choi (2006) etc. quantified changes in the indoor temperature by spraying water on the rooftops, and measuring the results. Theodosiou (2003), Yamasaki (2006), Castleton (2010) etc. analysed the effectiveness of reducing the cooling load through the evaporation effects of plants, by measurement and simulation. However, these previous studies were focused on a specific cooling method, and it is hard to find any study cases that compare various passive cooling methods. Also, most of the studies are limited to the building's indoor problems such as indoor load or thermal comfort, and it is hard to find any studies related to the aspect of heat islands in cities, which is a big issue nowadays.

For these reasons, an experiment was carried out with various finishing materials, to compare the effect of the absorption factor of solar radiation and evapotranspiration. Additionally, numerical simulations were carried out and the effect of indoor energy saving, and the relaxation effect of heat islands in cities were analysed. In the outdoor experiment, various test 
Table 1. Outline of the Test Pieces

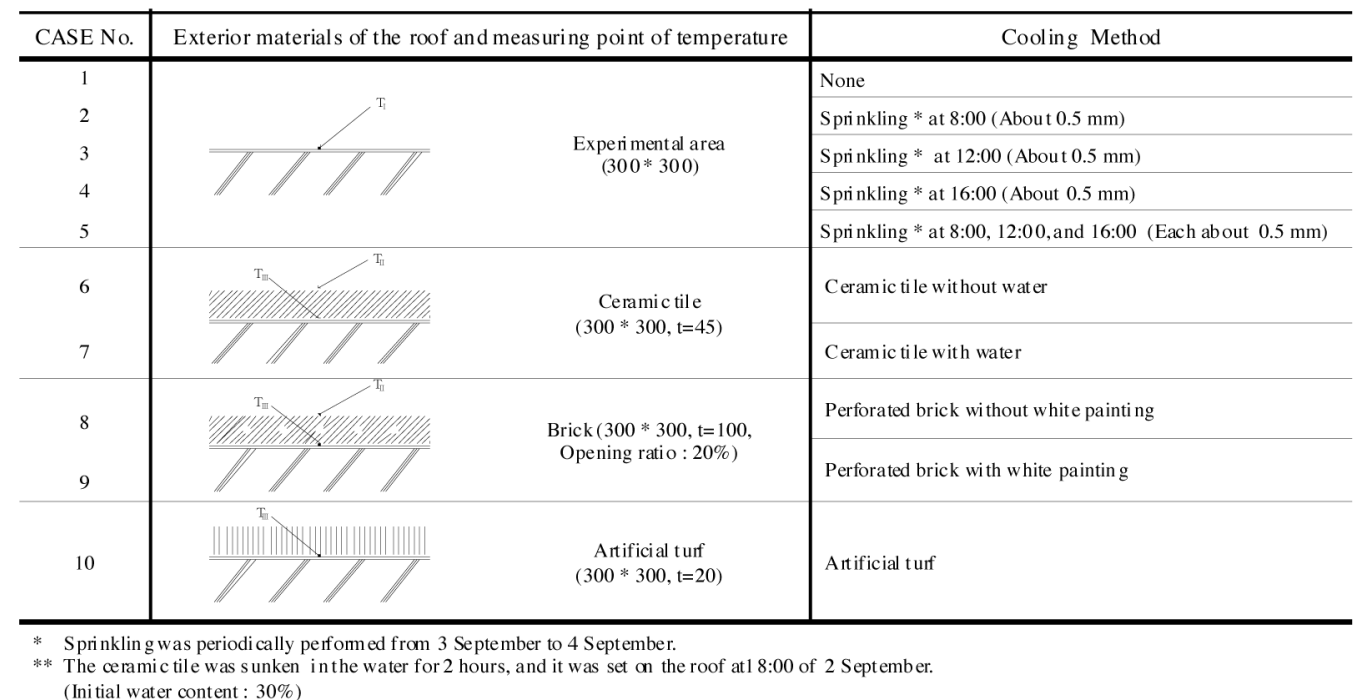

pieces were installed on an existing rooftop to examine the change in the surface temperature on a clear, summer day. Next, numerical calculation was carried out assuming different states of insulation in order to clarify the influence of rooftop surface cooling on the thermal load both indoors and outdoors in summertime.

\section{Experimental Outline}

\subsection{Research building of experimental blocks}

The experiment was conducted on the rooftop of the Main Research Building at the Building Research Institute. The building used as a subject was a 7-story $\mathrm{RC}$ building; the rooftop finish was asphalt roofing.

Table 1. shows the outline of the test specimens.

Two cases were assumed; one with the test section of asphalt roofing (AR, hereafter) only, and another with that of water-permeable tile (ceramic), perforated bricks (red bricks) and artificial turf (polyethylene resin). The test specimens were installed directly onto the rooftop slab. Based on the unit of $300 * 300 \mathrm{~mm}$, a $300 \mathrm{~mm}$ interval was placed between individual test specimens to prevent any influence on the adjacent section. Experimental data in this thesis was analysed based on the one dimensional method. The validity of the test specimen was checked by preliminary tests. ${ }^{1)}$

From the three environmental aspects of "latent heat of evaporation, "ventilation and "solar reflection, three types of passive cooling methods were applied:

(a) watered AR surface (Cases 2 5)

(b) ceramic tiles with and without water content (Cases 6 and 7)

(c) perforated bricks with and without a coat of white paint (Cases 8 and 9)

In the case of (a), to compare the cooling effect at the time of sprinkling, a $0.5 \mathrm{~mm}$ sprinkling was performed once a day, in the morning, noon or evening $(8: 00,12: 00$ or 16:00) or three times a day (morning, noon and evening). In the preliminary test, when the amount of sprinkling exceeded $0.5 \mathrm{~mm}$, the AR surface overflowed. Thus, the authors set the one-time sprinkling amount to $0.5 \mathrm{~mm}$. In the cases of (b), after soaking the ceramic tiles for two hours, they were placed, with a $30 \%$ volume water content, in the test section, in the evening (18:00, September 2). In the cases of (c), white paint was applied to the surface.

The temperature $\left(\mathrm{T}_{\mathrm{II}}\right)$ at the upper test piece in (b) and (c) corresponds to the rooftop surface temperature when the test specimen is used as a rooftop finish.

However, in this study, $\mathrm{T}_{\text {II }}$ was expressed as the upper test specimen temperature in order to distinguish it from Cases 1 5, in which no test specimen was installed. $\mathrm{T}_{\mathrm{I}}$ in Case 1 was regarded as the nonmeasured rooftop surface temperature. The fact was then considered that $T_{I}, T_{I I}$, and $T_{\text {III }}$ had decreased compared to the surface temperature in other cases of different surface finishes and of a similar insulation structure as the cooling effect. The total measurement period was one week, from September 1 to 7, 2003. The main measurement items were the rooftop surface temperature (Tab. 1, $\mathrm{T}_{\mathrm{I}}$ ), the upper test specimen temperature (Tab. 1, $\mathrm{T}_{\mathrm{II}}$ ), the lower test specimen temperature (Tab. 1, $\mathrm{T}_{\mathrm{III}}$ ), the outside temperature, and solar radiation. The outdoor temperature was measured by an Assmann's aspiration psychrometer (approximately $1.2 \mathrm{~m}$ in height).

For other temperature measurements, the Type-E thermocouple was used and the results were recorded at 10-minute intervals. For general meteorological data such as wind direction, wind velocity and rainfall, the measured values from the nearest local weather station were utilized. During the measurement, the indoor temperature under the roof was maintained at $24^{\circ} \mathrm{C}$ by air conditioning.

\subsection{Result of the experiment}

Fig.1. shows the meteorological conditions during the test period. On fair days from September 3 6, the amount of solar radiation exceeded $800 \mathrm{~W} / \mathrm{m}^{2}$ and the highest daytime temperature was $30^{\circ} \mathrm{C}$. On September 3 , a $5 \mathrm{~mm}$ rainfall was recorded between 16:00 and 17:00. Using the actual measured data of September 


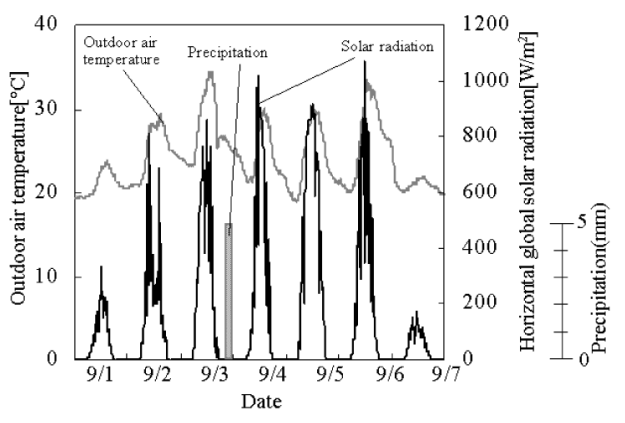

Fig.1. Weather Condition

3 (the highest temp: $34.5^{\circ} \mathrm{C}$ ) and September 4 after a rainfall, the cooling effect for each case was examined.

Fig.2. (a) shows the change in the rooftop surface temperature $T_{I}$ in Cases 1 5. Although a cooling effect on the surface temperature of several degrees was observed immediately after sprinkling in Cases 2 5, the effect was temporary.

The decrease in the upper test specimen temperature $\left(\mathrm{T}_{\text {II }}\right)$ can contribute to a reduction in the convective sensible heat on the atmosphere. Thus, by comparing the upper test specimen temperature $\left(\mathrm{T}_{\mathrm{II}}\right)$ to the rooftop surface temperature, the surface temperature difference was regarded as the cooling effect on the atmosphere.

Fig.2. (b) shows the change in the surface temperature and the upper test specimen temperature in Cases 6 9. First, the temperature difference $\Delta \mathrm{T}$ was compared between $\mathrm{T}_{\mathrm{I}}$ in Case 1 and $\mathrm{T}_{\mathrm{II}}$ in the other cases. Cases 6 and 8 showed a low surface temperature in the afternoon in comparison to Case 1.

Meanwhile, Cases 7 and 9 showed a large decrease in the surface temperature towards the middle of the day. $\Delta \mathrm{T}$ reached its maximum before and after 14:00 when the highest daytime temperature occurred, recording $-5.3^{\circ} \mathrm{C}$ in Case $6,-12.9^{\circ} \mathrm{C}$ in Case $7,-5.2^{\circ} \mathrm{C}$ in Case 8 and $9.1{ }^{\circ} \mathrm{C}$ in Case 9. After sunset, the differences between Cases $6 \sim 9$ were very small. By 5:00 when the lowest daytime temperature occurred, $\Delta \mathrm{T}$ were somewhere around -2.5 in all cases. Next, from the temperature difference $\Delta \mathrm{T}$ in $\mathrm{T}_{\mathrm{II}}$ between Cases 6 and 7 and between Cases 8 and 9, the effects of water content and white-paint coating were examined. In the comparison of surface temperature between the cases of water-permeable tiles with and without water content, a maximum temperature difference of $8.9^{\circ} \mathrm{C}$ was recorded. Comparing the cases with or without a white-paint coating, the maximum temperature difference was $7.4^{\circ} \mathrm{C}$. On September 4, there was no major difference in the surface temperature during daytime in Cases 6 and 7.

This was presumably because the amount of water content had been recovered to a significant extent in both cases because of the rainfall on the evening of September 3. Thus, it became clear that, when using water-permeable materials, the cooling effect for the

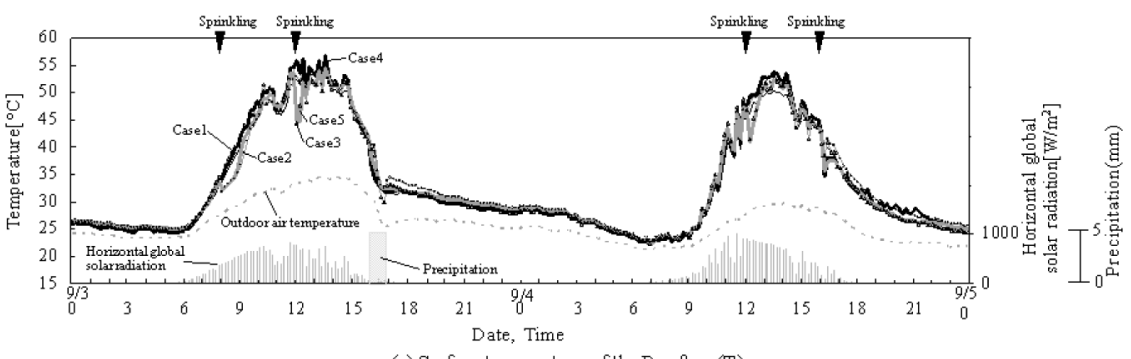

(a) Surface temperature of the Rooftop $\left(T_{p}\right)$
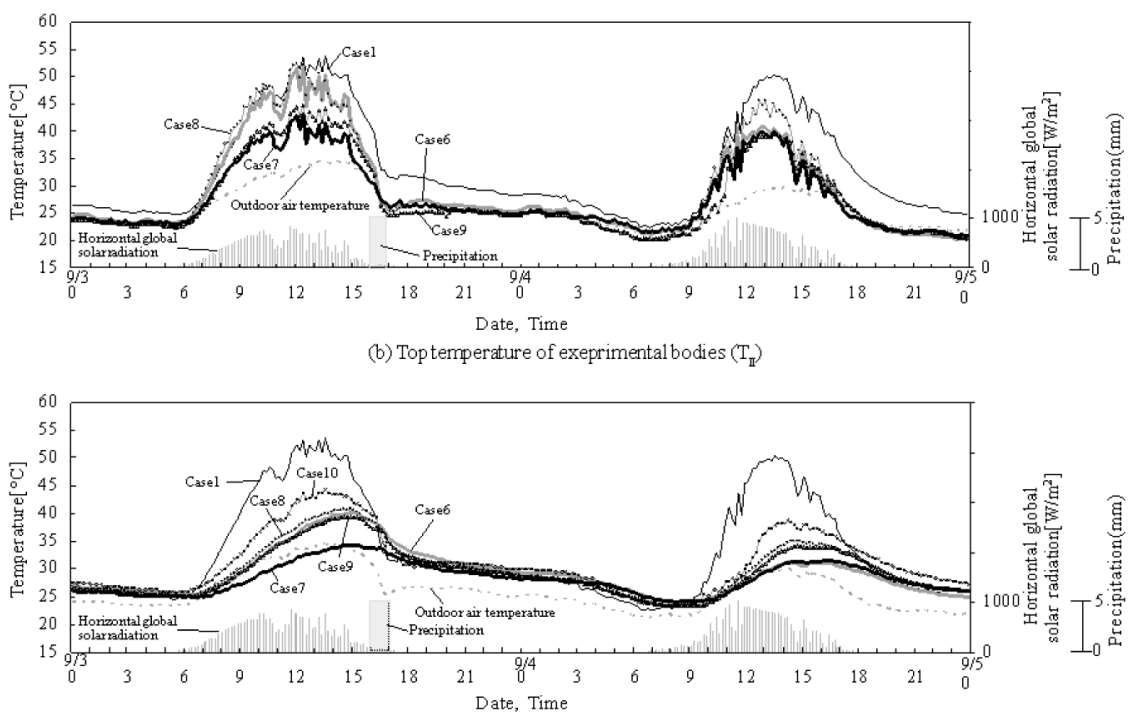

(c) Bottom temperature of experimental bodies ( $\left.T_{\text {II }}\right)$

Fig.2. Temperature Change of Outdoor Air, Surface Temperature of Rooftop, Top \& Bottom Temperature of the Test Specimens 
next day and later could be expected not only from human-induced sprinkling but also from natural precipitation in a temperate climate region.

The lower test specimen temperature $\left(\mathrm{T}_{\text {III }}\right)$ in each case is believed to contribute to the overall heat transfer into the room, while as a boundary condition for the rooftop slab, there is a time delay due to the heat transmission of the rooftop slab. Therefore, by comparing the lower test specimen temperature $\left(\mathrm{T}_{\text {III }}\right)$ to the rooftop surface temperature in Case 1, the surface temperature difference was regarded as an index for the cooling effect on the indoor side. Fig.2.

(c) shows the change in the surface temperature and the lower test specimen temperature in Case 1 and Cases 6 9. As a general trend, the daily change in $\mathrm{T}_{\text {III }}$ in each case was observed to be 1 3 hours late in comparison to the change in the amount of solar radiation. Looking at $\mathrm{T}_{\mathrm{I}}$ in Case 1 and $\Delta \mathrm{T}$ (the temperature difference in $\mathrm{T}_{\text {III }}$ in the case), the difference was almost none at night. Yet, a relatively large cooling effect was obtained towards the middle of the day in Cases $6 \sim 10 . \Delta \mathrm{T}$ reached its maximum around 14:00 when the daytime temperature also reached its maximum, recording (a) $-20.3^{\circ} \mathrm{C}$ in Case 7 , (b) $-13.8 \sim-15.1^{\circ} \mathrm{C}$ in Cases 6,8 and 9 and (c) $-9.5^{\circ} \mathrm{C}$ in Case 10. (a) In Case 7, in which the greatest effect was observed, $\mathrm{T}_{\text {III }}$ was controlled in correspondence to the air temperature, blocking off most of the radiation heat. Similarly to the change in $T_{\text {II }}$ in Fig.2. (b), such effect lasted until September 4 because of natural precipitation. (b) The effects in Cases 6, 8 and 9 are believed to stem mainly from the heat capacity and heat resistance of the test specimen. In the case of the lower test specimen temperature, the difference with or without a white-paint coating was about $1.3^{\circ} \mathrm{C}$ maximum, which is not a particularly large number.

The reason for this is that the test was conducted under weak wind conditions that day; thus, in the end, the effect of removing heat from the radiation by the ventilation of perforated bricks was small. (c) In the case of artificial turf, although the cooling effect on the atmosphere could not be obtained, that on the indoor side was expected.

Fig.3. shows the time change in the surface temperature immediately before and after sprinkling. The change was proportional to the solar radiation at the time of sprinkling in the order of Morning (sprinkling) $<$ Evening $<$ Noon. On the other hand, the duration of the continuous effect was longer in the order of Noon (sprinkling) $<$ Evening $<$ Morning.

The duration is normally two hours or less with this type of sprinkling. Thus, to expect a continuous effect during daytime, one needs to use water-permeable materials.

From Fig.4., based on the discussion results above, the differences between $T_{I}$ in Case 1 and $T_{I I}$ and $T_{\text {III }}$ in other cases were obtained, and the decreases in surface temperature by day and night were then grouped. In G1 (Case 2 5), the decrease in the surface temperature was $1^{\circ} \mathrm{C}$ or lower for the entire day; a cooling effect on the atmosphere and the indoor side cannot be particularly expected. In G2 (Cases 6 and 8) and G3 (Cases 7 and 9), the decrease in the surface temperature of $3 \sim 4^{\circ} \mathrm{C}$ was observed for the entire day; a reduction in the heat load in the atmosphere can thus be expected. Especially in $\mathrm{G} 3$, the surface temperature dropped by more than $8^{\circ} \mathrm{C}$ during daytime. In G4 (Cases $6 \sim 10$ ), a decrease of $8^{\circ} \mathrm{C}$ or higher in the daytime surface temperature was observed; a cooling effect on the indoor side can thus be expected. One can deduce the following from these analysis results: Cases $6 \sim 10$ are effective in reducing the air-conditioning load during daytime; Cases 7 and 9 are effective in inhibiting the heat island phenomenon during daytime; and Cases 6 9 are effective in preventing the tropical night phenomenon.

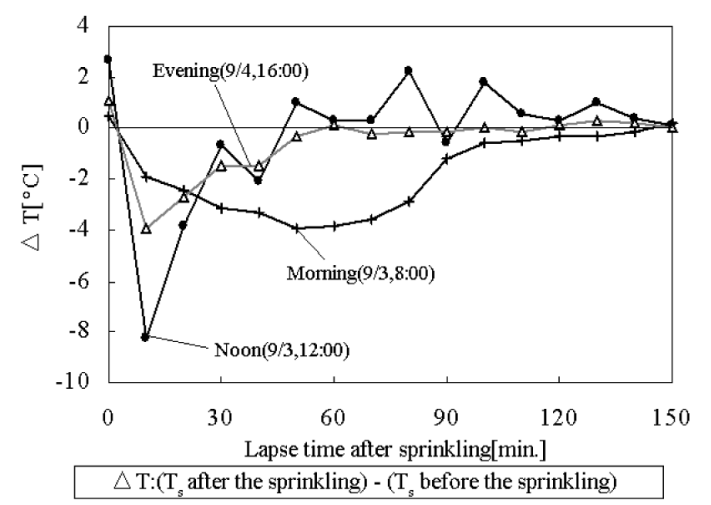

Fig.3. Lapse Time of Cooling Effect after Sprinkling

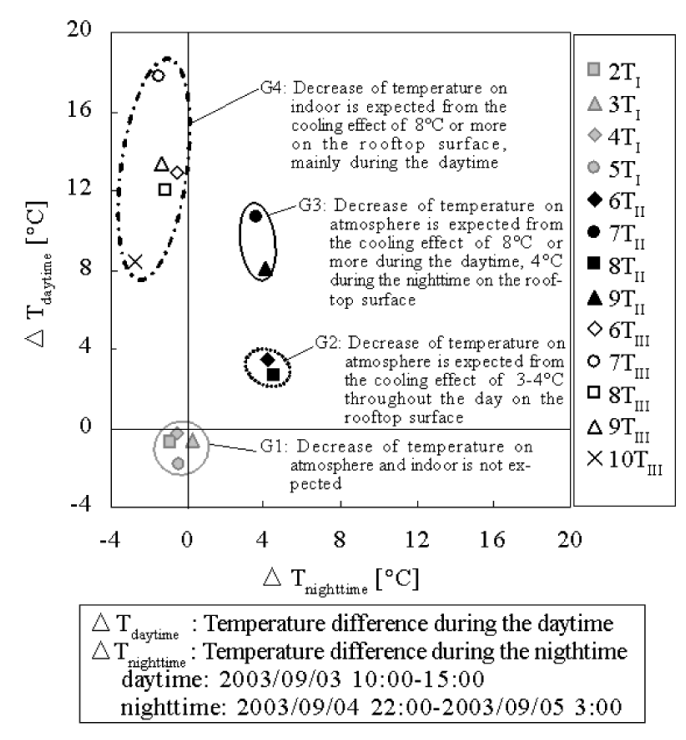

Fig.4. Cooling Effects during Daytime and Nighttime

\section{Calculation Outline}

To evaluate the influence of the rooftop surface cooling on the indoor heat load, a dynamic heat load calculation was conducted by the thermal circuit 
network method (Ishida et al., 1987). Furthermore, to evaluate the influence of the rooftop surface cooling on the atmospheric heat load, an unsteady heat conduction calculation of a one dimensional multi-mass system on the roof was conducted using the backward relaxation method, which made it possible to predict more detailed data such as a cross-sectional temperature distribution. For the evaporation and reflection of solar radiation on a building's outer surface, the new sol-air temperature was used, taking evaporation into consideration. Details of the $\mathrm{SAT}^{*}$ are given in the following:

$Q_{A}=Q_{R}-Q_{V}-Q_{I E}$

Since $Q_{R}=Q_{S}-Q_{I}$ Eq.(1) can be rewritten as follows: $\lambda(\partial \theta / \partial z)=Q_{S}-Q_{I}-Q_{V}-Q_{I E}$

Here,

$Q_{V}=\alpha_{c}\left(\theta_{s}-\theta_{a}\right)$

$Q_{S}=\left(1-\theta_{a}\right)$

and if $\varepsilon \sigma\left(T_{a}^{4}-T_{s}^{4}\right)=\varepsilon \alpha_{r}\left(\theta_{a}-\theta_{s}\right)$,

$Q_{I}=\varepsilon \sigma T_{s}^{4}-\left(1-K^{*} C C\right)^{*} B_{r}^{*} \varepsilon \sigma T_{a}^{4}-K^{*} C C \varepsilon \sigma T_{s}^{4}$ $=\left(1-K^{*} C C\right)\left[\left(1-B_{r}\right)^{*} \varepsilon \sigma T_{a}^{4}-\varepsilon^{*} \alpha_{r}\left(\theta_{a}-\theta_{s}\right)\right]$

Also, the saturation vapor pressure $\mathrm{f}_{\mathrm{s}}$ is expressed by the one-dimensional approximate equation

$\left(f_{S}=a^{*} \mathrm{q}_{\mathrm{s}}+b\right)$ of $\boldsymbol{\theta}_{s}$,

$Q_{I E}=w^{*} I^{*} \alpha_{w}\left(f_{s}-f_{a}\right)=a^{*} w^{*} \alpha_{w}\left(\theta_{s}-\theta_{a}\right)+$

$w^{*} I^{*} \alpha_{w}\left(a^{*} \theta a+\mathrm{b}-f_{a}\right)$

Eq. (6)

Organizing Equations (2) (6), the following equation can be obtained:

$-\lambda(\partial \theta / \partial z)=\alpha_{t}\left[\left(\theta_{a}+\theta_{e}^{*}\right)-\theta_{s}\right]$

Here, however, $\alpha_{t}$ and $\theta_{e}$ will be

$\alpha_{t}=\left(1-K^{*} C C\right)^{*} \varepsilon^{*} \alpha_{r}+\alpha_{c}+a^{*} w^{*} I^{*} \alpha_{w}$

$\theta_{e}{ }^{*}=\left[(1-\rho) J_{s}-\left(1-K^{*} C C\right)\left(1-B_{r}\right)^{*} \varepsilon \sigma T_{a}^{4}\right.$

$\left.-w^{*} I^{*} \alpha_{w}\left(b-f_{a}\right)\right] / \alpha_{t}$

In this study, $\left(\theta_{a}+\theta_{e}{ }^{*}\right)$ is handled as the sol-air temperature, taking evaporation into consideration (SAT*, hereafter). Fig.5. shows the results for which SAT $^{*}$ was calculated, using the hottest day. The maximum air-conditioning load was generated (August 5) from the standard weather data of Tokyo.

$\mathrm{SAT}^{*}$ dynamically changes depending on the solar reflectance ( $\rho$, hereafter) rather than the evaporation rate (w, hereafter). If the value is identical, the $\mathrm{SAT}^{*}$ with a value of $\rho$ that is greater than that of $w$ takes precedence. Here, based on the concept of the above SAT $^{*}$, the equivalent solar reflectance is proposed $\left(\rho^{*}\right.$, hereafter) to evaluate the effects of evaporation and the reflection of solar radiation. If equivalent outside air temperatures with evaporation in mind are equal, the effects of evaporation and solar reflection are considered to be equal. In the following, a numerical analysis was conducted with $\rho^{*}$ as the main parameter.

Figs.6. and 7. show the floor plan of the building and the rooftop slab structure in the indoor heat load calculation. For the subject, an office building was envisioned; the plan for the room was created based on standard office simulations of AIJ (Architectural Institute of Japan). The rooftop surface temperatures can vary considerably depending not only on the surface finish but also on the insulated state of the rooftop slab. For this reason, a calculation was performed for the case with no insulation (thermal resistance: $0.51 \mathrm{~m}^{2} \mathrm{~K} / \mathrm{W}$ ) on the rooftop slab.

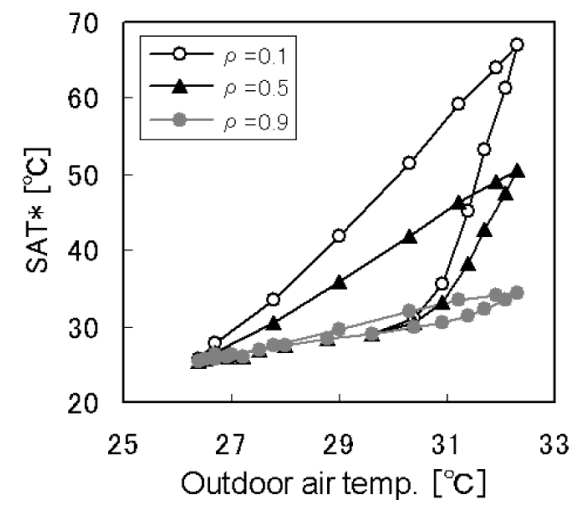

(a) Relationship between $\rho$ and $\operatorname{SAT}^{*}(w=0.0)$

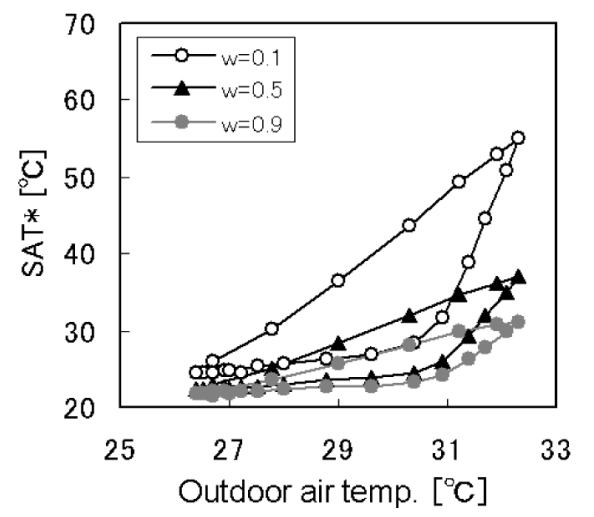

(b) Relationship between wand $\operatorname{SAT}^{*}(\rho=0.1)$

Fig.5. Relationship between $\rho, w$ and Outdoor Air Temperature

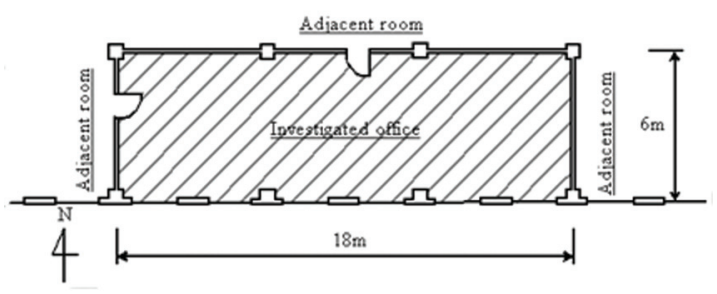

Fig.6. Floor Plan of the Building for the Calculation

Then, after changing the thickness of the insulation material in five stages, a calculation was conducted for the case of internal insulation (thermal resistance: $0.87 \sim 5.88 \mathrm{~m}^{2} \mathrm{~K} / \mathrm{W}$ ) on the rooftop slab. Table 2 . shows various input conditions used to calculate the indoor heat load. Air conditioning was set to operate between 8:00 and 18:00 and the fixed temperatures 


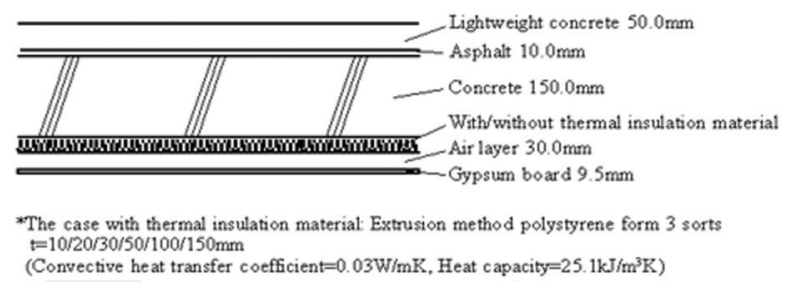

Fig.7. Rooftop Slab Structure for the Calculation

for air conditioning and heating were set at $26^{\circ} \mathrm{C}$ and $22^{\circ} \mathrm{C}$ respectively. Inside the building, the heat generation of $25 \mathrm{~W} / \mathrm{m}^{2}$ from lighting and equipment was established. The convection heat-transfer rate on the indoor side and outdoor side was 11.1 and $25.0 \mathrm{~W} /$ $\mathrm{m}^{2} \mathrm{~K}$ respectively.

Table 2. Input Conditions for the Calculation

\begin{tabular}{|c|c|c|c|}
\hline \multirow{2}{*}{$\begin{array}{l}\text { Data } \\
\text { kinds } \\
\text { Weather } \\
\text { data } \\
\end{array}$} & \multicolumn{3}{|l|}{ Input conditions } \\
\hline & \multicolumn{3}{|c|}{ Standard weather data of the average year of the SHASE } \\
\hline \multirow{5}{*}{$\begin{array}{l}\text { Room } \\
\text { outline } \\
\text { and } \\
\text { indoor } \\
\text { conditions }\end{array}$} & Size & $\begin{array}{l}\text { Area } \\
\text { Story height }\end{array}$ & $\begin{array}{l}108 \mathrm{~m}^{2} \\
3.6 \mathrm{~m}\end{array}$ \\
\hline & $\begin{array}{l}\text { Conditions of } \\
\text { air-conditioning }\end{array}$ & $\begin{array}{l}\text { Setup temp. for cooling } \\
\text { Setup temp } \\
\text { Air-conditioning time } \\
\text { Ventilation rate }\end{array}$ & $\begin{array}{l}26^{\circ} \mathrm{C} \\
22^{\circ} \mathrm{C} \\
8 \mathrm{am}-6 \mathrm{pm} \\
1.0 \mathrm{ACH}\end{array}$ \\
\hline & $\begin{array}{l}\text { Indoor heat } \\
\text { generation }\end{array}$ & $\begin{array}{l}\text { Lighting } \\
\text { Instrument } \\
\text { Person } \\
\end{array}$ & $\begin{array}{l}20 \mathrm{~W} / \mathrm{m}^{2} \\
5 \mathrm{w} / \mathrm{m}^{2} \\
0.2 \mathrm{person} / \mathrm{m}^{2}\end{array}$ \\
\hline & $\begin{array}{l}\text { Convective heat } \\
\text { transfer } \\
\text { coefficient }\end{array}$ & $\begin{array}{l}\text { Indoor side } \\
\text { Outdoor side }\end{array}$ & $\begin{array}{l}11.1 \mathrm{~W} / \mathrm{m}^{4} \mathrm{~K} \\
25.0 \mathrm{~W} / \mathrm{m}^{4} \mathrm{~K}\end{array}$ \\
\hline & Others & Indoor heat capacity & $12.6 \mathrm{KJ} / \mathrm{m}^{4} \mathrm{~K}$ \\
\hline \multirow{4}{*}{$\begin{array}{l}\text { Thermal } \\
\text { boundary } \\
\text { data }\end{array}$} & Rooftop & $\begin{array}{l}\text { Equivalent solar } \\
\text { reflectance * } \\
\text { Thermal resistance }\end{array}$ & $\begin{array}{l}0.1 \sim 0.9 \\
0.51 \sim 5.88 \mathrm{~m}^{2} \\
\mathrm{KW}\end{array}$ \\
\hline & & Thern & 0.9 \\
\hline & Exterior wall & $\begin{array}{l}\text { Solar reflectance } \\
\text { Thermal emittance } \\
\text { Thermal resistance }\end{array}$ & $\begin{array}{l}0.1 \\
0.9 \\
2.11 \mathrm{~m}^{2} \mathrm{KW}\end{array}$ \\
\hline & Window & $\begin{array}{l}\text { Solar permeability } \\
\text { Solar shading } \\
\text { coefficient }\end{array}$ & $\begin{array}{l}0.29 \\
0.125\end{array}$ \\
\hline
\end{tabular}

\section{Result of the Calculation}

Fig.8. shows the integrating value of air-conditioning load on the hottest day in Tokyo with atmosphere $\rho^{*}=0.1 \sim 0.9$ under different insulated states of the rooftop slab. Fig.9. shows the convective heat flux from the rooftop during the daytime under the same conditions. When the rooftop is insulated, the airconditioning load decreases (Fig.8.). The thermal resistance level of the rooftop slab was particularly conspicuous in its drop rate between no insulation and the standard for the next-generation energy-saving level of Japan $\left(2.29 \mathrm{~m}^{2} \mathrm{~K} / \mathrm{W}\right)$. Even for the building without insulation, the effect of air-conditioning load reduction corresponding to that in the next-generation energy-saving level could be obtained by implementing a rooftop cooling of $\rho^{*}=0.9$.

By comparison, as the thermal resistance value of the rooftop increases, the convective heat flux from the rooftop during daytime increases (Fig.9.).

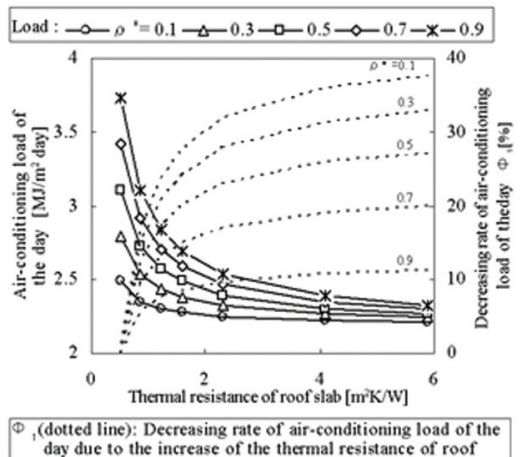
day due to the increase of the thermal resistance of roof
slab, comparing to the condition of no thermal insulation

Fig.8. Air-Conditioning Load during the Day (Tokyo, the Hottest Day)

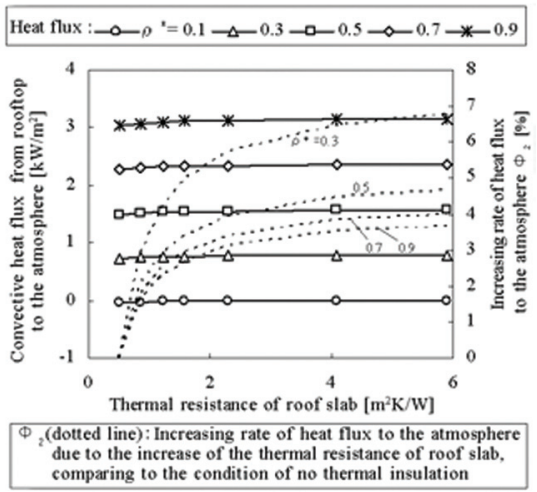

Fig.9. Convective Heat Flux to the Atmosphere during the Daytime (Tokyo, the Hottest Day, 10:00 15:00)

However, the increase rate was merely $2 \sim 3 \%$, a small figure compared to the air-conditioning load.

Fig.10. shows the relationship between the daytime and nighttime rooftop surface temperatures and the heat flux to the indoor side and the outdoor side air on the hottest day in Tokyo.

In the daytime, there was a correlation between the $\rho^{*}$ value and the rooftop surface temperature; as the $\rho^{*}$ value increased by 0.2 , the surface temperature decreased by $5.3 \sim 5.5^{\circ} \mathrm{C}$ (Fig. 10. (a)).

The rooftop surface temperature changed significantly depending on the $\rho$ value rather than on the insulated state of the rooftop slab. When $\rho^{*}=0.1$, the rooftop surface temperature was $21.0^{\circ} \mathrm{C}$ higher than the outdoor temperature. As the surface temperature increased, the heat flux to the indoor side and the atmosphere also increased. Yet, by strengthening the insulation, the heat transfer could be controlled to a low level.

Similarly, at nighttime, as the $\rho^{*}$ value increased, the rooftop surface temperature decreased (Fig.10. (b)). It is believed that the increase in the $\rho^{*}$ value helped the effect of inhibiting the daytime thermal storage.

Similarly to the daytime, as the surface temperature increased, the heat flux to the indoor side and the atmosphere also increased. Yet, when the surface temperature reached below the outdoor air temperature, the heat flux value to the atmosphere side became 
negative. Thus, the heat flux to the atmosphere was negative when the $\rho^{*}$ value was 0.7 or greater, regardless of the insulated state of the rooftop slab. The above findings clarified that the rooftop surface temperature was closely related to both the heat load to the atmosphere and the indoor heat load. This suggests that observed values of the rooftop surface temperature in Fig.4. played a significant role in measuring the thermal performance of the rooftop slab.
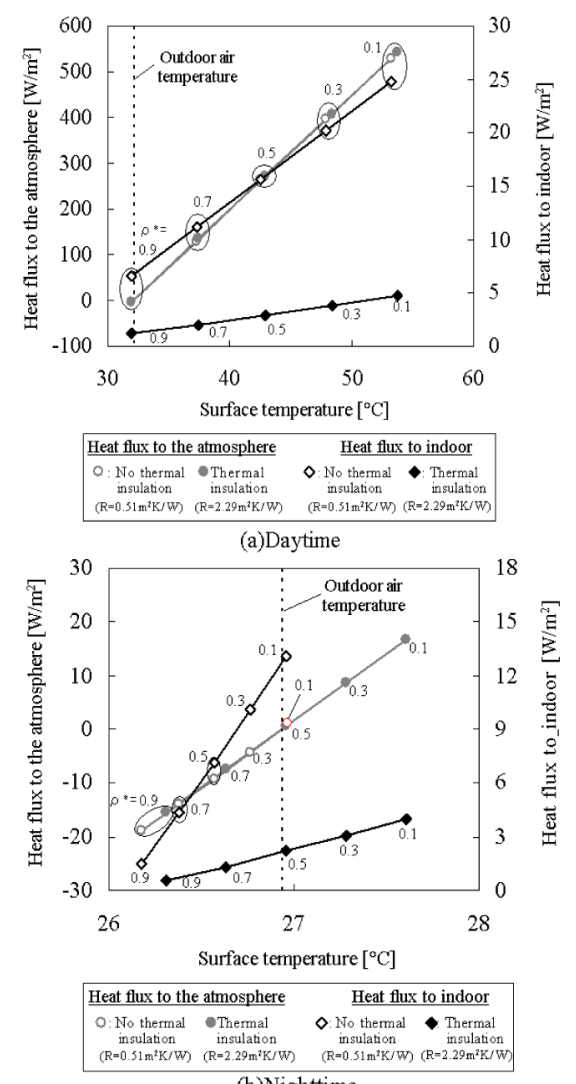

(b) Nighttime

Fig.10. Average Rooftop Temperature During the Daytime and the Nighttime, and Heat Flux to Indoor and the Atmosphere (Tokyo, the Hottest Day, Daytime: 10:00 15:00, Nighttime: 22:00 Following 3:00)

Fig.11. shows the daily integrating value of the airconditioning load on the hottest day when $\mathrm{w}$ and $\rho$ changed to 0.1 and 0.9 respectively. It became clear that even when the rooftop slab was not insulated, an energy-saving performance similar to that in the next-generation insulation standard of Japan (thermal resistance $=2.29 \mathrm{~m}^{2} \mathrm{~K} / \mathrm{W}$ ) could be obtained from $\rho: 0.5$ or greater $(w=0.0)$ and $w: 0.1$ or greater $(\rho=0.1)$. It also became clear that, with $\rho: 0.5$, an effect of airconditioning load reduction similar to that with w: 0.1 could be obtained. Also, it was confirmed that, regardless of the insulated state of the rooftop slab, with an increase in $\rho$, w would contribute to the reduction in the indoor air-conditioning load.

Up to this point, the cooling effect of the rooftop surface in summertime has been examined. In winter, it is believed that the reverse effect such as a heating load increase occurs. Therefore, an annual load calculation was performed, targeting the regions that have different climate conditions, and a yearlong evaluation was conducted.

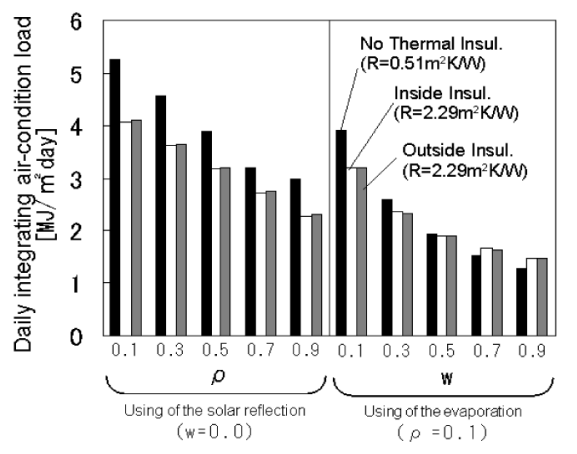

Fig.11. Daily Integrating Air-Condition Load and w, $\rho$ (Tokyo, the Hottest Day)

Fig.12. shows the integrating value of the regionby-region annual air-conditioning load on the noninsulated rooftop slab when $\rho^{*}: 0.1,0.5$, and 0.9 .

As $\rho^{*}$ increased, the cooling load reduced and the heating load increased. This problem of the heating load increase can be resolved by passive actions such as watering only in summertime using water-retentive materials on the rooftop. However, the details will be a future task. In Tokyo, the cooling load, which had been reduced due to the rise in $\rho^{*}$, was offset by the increase in the heating load and showed no change as the annual air-conditioning load.

However, the problem of the peak electric power in summer was one of the major tasks in terms of energy issues. Thus, it is believed that, in regions south of Tokyo, one should strive to decrease the surface temperature on the rooftop surface.

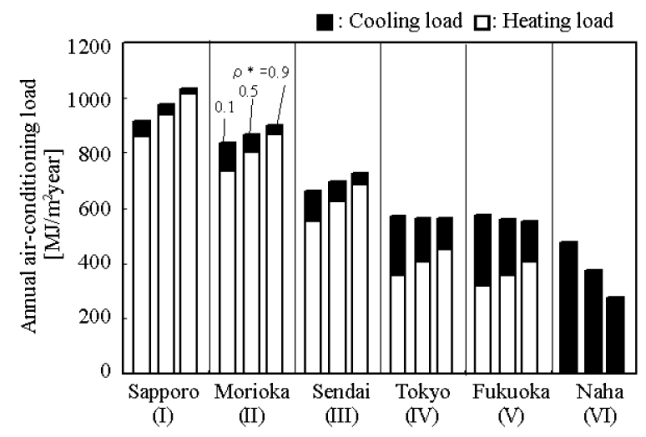

Fig.12. Annual Air-Conditioning Load of Several Regions in Japan (RC Structure, Roof Slab: No Thermal Insulation)

\section{Conclusion}

In this study, an outdoor experiment was conducted using test specimens with a focus on the passive cooling on the rooftop surface in summertime to clarify the cooling effect of various types of passive cooling. Influence of the rooftop cooling on the indoor heat load 
and the influence of the heat load on the atmospheric side were also clarified. The findings are as follows:

1. A total of 10 types of experimental data were collected; Case 1 is an AR surface, Cases 2 5 are watered AR surfaces, Cases 6 and 7 are ceramic tiles, with and without a water coat or white paint respectively, Cases 8 and 9 are perforated bricks, with and without a coat of white paint respectively, and finally, Case 10 is an artificial turf (polyethylene resin). Results of data analysis for Cases 6 10 show that because these types can reduce the load on the air during the day, they are effective. For Cases 7 and 9, during the day, the heat island effect is suppressed. For Cases 6 9, the tropical night phenomenon can be prevented. For Cases 2 5, the decrease in the surface temperature was $1{ }^{\circ} \mathrm{C}$ or lower for the entire day; a cooling effect on the atmosphere and the indoor side cannot be expected.

2. It was discovered that, even when the insulation work on the rooftop slab is incomplete, an energysaving performance similar to that in the nextgeneration insulation standards could be achieved with a solar reflectance of 0.5 or greater and an evaporation rate of 0.1 or greater.

3 . From the calculated findings of the region-byregion annual air-conditioning load, it was noted that regions where the cooling of the rooftop surface would be effective throughout the year are the regions south of Tokyo.

\section{Symbols}

1) subscript a: atmosphere

2) subscript s: surface

3) subscript t: physical quantity at thickness $t$

4) $Q_{R}$ : radiant heat transfer $\left[\mathrm{W} / \mathrm{m}^{2}\right]$

5) $\mathrm{Q}_{\mathrm{S}}$ : heat transfer by short wave radiation $\left[\mathrm{W} / \mathrm{m}^{2}\right]$

6) $\mathrm{Q}_{1}$ : heat transfer by long wave radiation $\left[\mathrm{W} / \mathrm{m}^{2}\right]$

7) $\mathrm{Q}_{\mathrm{V}}$ : sensible heat transfer $\left[\mathrm{W} / \mathrm{m}^{2}\right]$

8) $\mathrm{Q}_{\mathbb{E}}$ : latent heat transfer $\left[\mathrm{W} / \mathrm{m}^{2}\right]$

9) $\mathrm{Q}_{\mathrm{A}}$ : conductive heat transfer $\left[\mathrm{W} / \mathrm{m}^{2}\right]$

10) $\alpha_{\mathrm{c}}$ : convective heat transfer coefficient $\left[\mathrm{W} /\left(\mathrm{m}^{2} \mathrm{~K}\right)\right]$

11) $\alpha_{\mathrm{r}}$ : radiant heat transfer coefficient $\left[\mathrm{W} /\left(\mathrm{m}^{2} \mathrm{~K}\right)\right]$

12) $\alpha_{w}$ : moisture transfer coefficient $\left[\mathrm{W} /\left(\mathrm{m}^{2} \mathrm{~h}\left(\mathrm{~kg}^{\prime} / \mathrm{kg}\right)\right)\right]$

13) $\rho$ : reflectance $[-]$

14) $\varepsilon$ : emittance $[-]$

15) $\sigma$ : Stefan-Boltzmann constant $\left[\mathrm{W} /\left(\mathrm{m}^{2} \mathrm{~K}^{4}\right)\right]$

16) $\mathrm{B}_{\mathrm{r}}$ : ratio of emission [-]

17) $\mathrm{J}_{\mathrm{s}}$ : solar radiation $\left[\mathrm{W} / \mathrm{m}^{2}\right]$

18) $\mathrm{T}$ : absolute temperature $[\mathrm{K}]$

19) $\theta$ : temperature $\left[{ }^{\circ} \mathrm{C}\right]$

20) K: height coefficient of clouds $[=0.62]$

21) CC: amount of clouds [-]

22) a, b: coefficient of one-dimensional approximate equation of saturation vapour pressure [-]

23) w: evaporation efficiency [-]

24) f: vapour pressure $\left[\mathrm{kg}^{\prime} / \mathrm{kg}\right]$

25) 1: latent heat of evaporation of water $[=2512 \mathrm{~kJ} / \mathrm{kg}]$

26) $\lambda$ : thermal conductivity $[\mathrm{W} /(\mathrm{mK})]$
Note

A preliminary experimental study was carried out using a $300 * 300 \mathrm{~mm}$ size ceramic tile and a $1000 * 1000 \mathrm{~mm}$ size ceramic tile, and it was noted that the temperatures were almost the same with a slight temperature difference of $0.2^{\circ} \mathrm{C}$. Also, it was noted, that the temperature difference between the center point of the test specimen $(300 * 300 \mathrm{~mm})$ and two compensational temperature measurement points, which were $150 \mathrm{~mm}$ away from the center point of the test body, was within $-0.2 \sim+0.1^{\circ} \mathrm{C}$.

\section{Acknowledgement}

This research was supported by the Basic Science Research Program through the National Research Foundation of Korea (NRF) funded by the Ministry of Education, Science and Technology (2010-0028154).

\section{References}

1) Ichinose, T., Shimodozono, K. and Hanaki K. (1999) Impact of anthropogenic heat on urban climate in Tokyo, Atmospheric Environment 33, Elsevier Science Ltd., pp.3897-3909.

2) M.T.R. Jayasinghe, R.A. Attalage, A.I. Jayawardena (2003) Energy for Sustainable Development, Volume 7, Issue 1, pp 16-27.

3) Ishikawa Yukio, Misaka Ikusei, Kitano Hiroaki (2008) Evaporative Cooling Effect of Wall and Roof with the Use of Thermo-sensitive Hydroge, Architectural Institute of Japan, pp.537-538.

4) Takahashi Itaru, Kuroiwa Akihiko (2003) Development of a Passive Cooling Strategy Using Double-Roofing System with Water Spraying and Its Field Testing in Terms of The Indoor Thermal Environment, Architectural Institute of Japan, pp.55-61.

5) Choi Dong-Ho, Lee Bu Yong (2006) An Evaluation on Effects to Affect Indoor Thermal Environment of The Top Floor caused by Evaporative Cooling of Roof Water Spraying, Architectural Institute of Korea, pp.271-278.

6) Theodore G. Theodosiou (2003) Summer period analysis of the performance of a planted roof as a passive cooling technique, Energy and Buildings, Volume 35, Issue 9, pp.909-917.

7) Yamasaki Mariko, Mizutani Akio, Ohsawa Tetsuo (2006) Green Roof and Green Wall Influence on Air Condition Load Decrease, Architectural Institute of Japan, pp.651-652.

8) H.F. Castletonm V. Stovin, S.B.M. Beck, J.B. Davison (2010) Energy and Buildings, Volume 42, Issue 10, pp.1582-1591.

9) Ishida, K. and Udagawa, M. (1987) A practical method for calculation of room temperature in multi-room building, Journal of architecture, Planning and environmental eng., Architectural Institute of Japan, pp.46-55. 